\title{
Winter Fat Storage and Vertical Microenvironmental Gradients: Experimental Test of an Alternative Hypothesis
}

\author{
Christopher M. Rogers*
}

Department of Biological Sciences, Wichita State University, Wichita KS 67260, USA

\begin{abstract}
Cost-benefit optimal body mass models have become a cornerstone of behavioral ecology of the nonbreeding period of birds, and make the prediction that fat will increase with increasing deterioration of feeding conditions. Tests of this prediction have relied on comparing fat stores of birds along a vertical height gradient of resource unpredictability (greater snowfall nearer the ground), and lower fat levels in tree-feeders compared with ground-feeders supported the prediction in previous studies. Alternatively, as predation risk is often cited as a cost of fat storage, lower fat stores may be caused by greater predation risk higher in the vertical resource gradient compared with the ground microenvironment. Among three species of tree-feeding birds wintering in south-central Kansas, foraging birds frequently preferred a higher sunflower feeder over a similar lower one, with blind and microenvironmental effects considered indirectly. Interspecific dominance rank was significantly and positively correlated with body size. Social dominants frequently displaced subordinates from the higher to the lower feeder. Thus a minimum of fat in tree-feeding species that can be explained by predictable resources (low snowfall), not high costs, underscoring the low benefit to fat in this winter foraging guild. Future resource-based tests of optimal fat models will need to measure both costs and benefits of fat in different winter foraging guilds.
\end{abstract}

Key Words: Winter, fat, birds, predation, foraging, optimality.

\section{INTRODUCTION}

The dynamics of fitness maximization in non-breeding birds are described by models of adaptive fat regulation. The set of adaptive fat models views avian fat storage as a starvation-predation trade-off: by balancing the costs and benefits of fattening, winter survival, a surrogate fitness variable, is maximized [1-4]. Reduced starvation risk is considered a main benefit of fat, and fat is predicted to increase in environments of uncertain foraging gain; increased predation risk (lowered flight performance and/or exposure to predators while feeding) is a likely cost of avian body fat storage, especially at high fat levels [5-9; reviewed by 10].

There is considerable support for the model prediction of increased fat level under increased starvation risk caused by deteriorating feeding conditions [11-18]. Recent tests involving natural populations include comparing species populations between environments of differing resource predictability, represented by an altitudinal gradient $[19,20]$, a vertical microenvironmental gradient of snowfall probability in the north temperate winter [21], or a combination of latitude and the vertical snowfall gradient [22].

Studies relying on the vertical snowfall (resource) gradient make the assumption that additional ecological gradients affecting guild-specific fat level are absent. Yet, a vertical gradient of predation risk affecting the fat reserve is possible: predation risk may be higher in the trees than nearer the

*Address correspondence to this author at the Department of Biological Sciences, Wichita State University, Wichita KS 67260, USA; Tel: 316-9786767; Fax: 316-978-3772; E-mail: chris.rogers@wichita.edu ground, causing the lower fat levels observed in the treeforaging guild, and allowing higher fat levels among groundforaging species. This alternative hypothesis is based on standard cost-benefit models of avian adaptive body mass, which view predation as a factor reducing avian fat levels when high, and permitting larger reserves when low. Such an effect of predation would minimize the significance of tests of optimal body mass theory that rely on the assumed vertical height gradient of resource predictability. The predationgradient hypothesis predicts that tree-feeders will prefer a lower feeder when similar sources of supplemental food are presented at different vertical heights to wintering mixedspecies flocks.

\section{MATERIALS AND METHODOLOGY}

\section{Study Site and Species}

Experimental tests of the prediction were conducted at the Ninnescah Field Station (NFS), which consists of 133 hectares located along the Ninnescah River in southwestern Sedgwick County, Kansas $\left(37^{\circ} 32^{\prime} N 97^{\circ} 41^{\prime} W\right)$. The NFS is located in the Wellington Lowlands physiographic province in the midgrass prairie transition zone between eastern tallgrass prairie and western shortgrass prairie. The site includes remnants of unplowed midgrass prairie, restored midgrass prairie, riparian woodland, prairie marsh, and ephemeral pool ecosystems. A 6.9 hectare area of mature riparian woodland is dominated by cottonwood (Populus deltoides), hackberry (Celtis occidentalis), box elder (Acer negundo) willow (Salix sp.) and juniper (Juniperus sp.). The field station supports a diverse avian community of permanent resi- 
dents, including the Black-capped Chickadee (Poecile atricapillus), Tufted Ttitmouse (Baeolophus bicolor), Redbellied (Melanerpes carolinus), Downy (Picoides pubescens), and Hairy (P. villosus) woodpeckers, White-breasted (Sitta caroliensis) and occasional Red-breasted (S. canadensis) nuthatches, and the Northern Cardinal (Cardinalis cardinalis). Wintering migratory species include the Dark-eyed Junco (Junco hyemalis), American Goldfinch (Carduelis tristis), and American Tree (Spizella americana), Song (Melospiza melodia), Harris (Zonotrichia querula), Whitethroated (Z. albicollis) and White-crowned (Z. leucophrys) Ssparrows. Based on color-banding of mixed-species flocks in the two study winters and in previous field seasons [23], these permanent resident species formed three different flocks in different locations within the field station, and wintering migrants regularly joined these flocks. The winter community of diurnal predators on small birds included the Cooper's (Accipiter cooperi) and Sharp-shinned hawks (A. striatus). Red-tailed Hawks (Buteo jamaicensis) occur at the site, but spend most time in open habitats. No shrikes (Lanius sp.) were observed wintering at the site. No Northern Pygmy Owls (Glacidium gnoma), the only other significant diurnal predator on adult small birds in North America, occur within approximately 425 miles of the study site [24], and none has ever been sighted in Kansas [25]. A significant population of Eastern coyotes (Canis latrans) inhabits the field station and surrounding landscape, and feral cats are absent from the field station tract.

\section{Fat Levels}

Winter fat levels of tree-and ground-foraging bird species at the NFS have already been measured, with members of the former showing significantly lower levels than the latter guild [23].

\section{Feeder Design}

Experimental feeders were single-hopper 16" columns fitted with a large metal seed reservoir above, mounted on a 11 " x 11" painted plywood base fitted with two black-taped aluminum dowel perches, 6" apart on one side of the base. A $1 / 2$ " mesh hardware cloth cylindrical shield ran from the reservoir rim down to the wood base, and a 4" x 2 " opening centered between the two perches offered the only access to the hopper. Small black oil sunflower seed was the sole food source in experimental feeders. This design facilitated birds of various species landing on the perch, acquiring a single seed from the hopper, and departing to husk the seed in nearby wooded vegetation. Often two birds, conspecifics or not, landed on different feeder perches close in time, with one individual displacing the other.

\section{Feeder Presentation}

At each of three sites, each inhabited by a different mixed-species wintering flock, two feeders were established at different heights in November of 2003 and 2006, for a total of six site-year combinations. Different sites (habitat surrounding experimental feeders) at which feeders were placed were chosen to represent the range of typical habitat structure occupied by wintering flocks. At site 1, the upper feeder was placed at $4.5 \mathrm{~m}$, and a lower feeder $1.7 \mathrm{~m}$ above ground in a juniper patch overlaid by taller deciduous trees lacking leaves. An observation blind was placed $12 \mathrm{~m}$ from the feeders. All upper feeders were suspended by rope from an upper tree branch, and all lower feeders were suspended from the bottom of the upper feeder. Guy ropes (1/feeder) stabilized feeders in wind. At all sites, branches were trimmed as necessary to maintain a constant distance of 1.5 $\mathrm{m}$ from a given feeder and the nearest perch. At site 2, the upper feeder was placed $6.6 \mathrm{~m}$, and a lower feeder $1.9 \mathrm{~m}$, above ground in a large cottonwood tree on the edge of a wooded riparian strip bordered by grassland, with a blind placed $26 \mathrm{~m}$ away. Details of branch structure and available space dictated feeder heights and feeder-blind distance at sites 1 and 2. At site 3, an upper feeder was placed $5.5 \mathrm{~m}$, and a lower feeder $2.2 \mathrm{~m}$, above ground along the southfacing edge of a large riparian tract bordered by grassland. A blind was placed $100 \mathrm{~m}$ from site 3 feeders, in order to observe avian feeder use in the assumed absence of any potential blind effect on feeder selection. Any blind effect on feeder choice at site 3 at this distance cannot be excluded completely, but is expected to be negligible, particularly as the blind was both low in profile and placed among tall grasses and forbs. Testing a blind effect using greater feederblind distances would face significant practical difficulties involving an investigator's ability to see birds using experimental feeders.

\section{Observation of Feeder Use}

Bird use at each feeder was recorded from blinds during 30-minute observation periods, distributed in the morning and afternoon, November-March 2003-04 and 2006-07. Individual bird visits to feeders are considered independent because birds made short-term decisions about which feeder to use (see Discussion). All visits to feeders by all species using them was recorded with respect to feeder selection (upper or lower), result of intraspecific or interspecific dominance interactions, and any post-dominance interaction feeder selection. In addition, when any individual of any species visited a feeder to obtain a seed, the presence of any other individual(s) at the nonselected feeder was recorded.

Data were pooled over winters and a linear interspecific dominance hierarchy was observed, in which each species regularly dominated (or was dominated by) all species below (or above) it. To investigate the relationship between social dominance rank and body size, body mass data on species wintering at the field station and other local sites [23] were used. Rank average afternoon body mass of different species was correlated with social dominance rank using the Spearman rank correlation coefficient.

Chi-square tests were used to compare observed frequency of feeder use with expected frequency use derived from the null hypothesis of 50:50 use of upper and lower feeders (no feeder preference). All expected values were greater than 5 . Separate tests were made for two different cases, upon determination of the interspecific dominance hierarchy. Case 1 is birds of a given species attending experimental feeders in the presence of conspecifics only, or with conspecifics and heterospecific social subordinates; this was assumed to represent the presence only of intraspecific competition for preferred feeder access. Chickadees and titmice attended feeders in flocks, but nuthatches often fed alone, and this is considered to be a low level of intraspecific 
competition. Case 2 is birds of a given species attending experimental feeders in the presence of conspecifics and heterospecific social dominants; this was assumed to represent a combination of intraspecific and interspecific competition for preferred feeder access. In the case of nuthatches feeding alone, without conspecifics (but in the presence of the only heterospecific social dominant to nuthatches, the Red-bellied Woodpecker), intraspecific competition is assumed to be at a low level. This general approach was used only for treefeeding species, although other species regularly used feeders, e.g. Dark-eyed Junco (ground feeder) and American Goldfinch (ground and tree feeder) and were regular participants in social dominance interactions.

\section{RESULTS}

\section{Interspecific Dominance Hierarchy}

A total of 109 interspecific displacements involving 6 species was observed in the two winters of the study (Fig. 1). Displacements occurred most frequently when one member of a species drove a member of a second species from one of the two perches on the feeder base, although several occurred on the edges of the base protruding from the mesh column surrounding the seed hopper, where spilled seeds collected occasionally. The dominance hierarchy featured only two reversals, involving the Black-capped Chickadee and American Goldfinch, with the latter defeating the former species 10 of 12 times. The Red-bellied Woodpecker dominated 5 other species, and the Black-capped Chickadee dominated no other species regularly. The Spearman rank correlation coefficient between body mass and dominance rank in this hierarchy was statistically significant $\left(\mathrm{r}_{\mathrm{s}}=0.943\right.$,
$\mathrm{P}<0.05)$. When the number of interactions between species in a pair was $<3$, the larger bodied species won $100 \%$ of the time.

\section{Feeder Use by the Black-capped Chickadee}

When Black-capped Chickadees were feeding with conspecifics in 2002-03, the higher feeder was visited significantly more often than the lower feeder at all three sites (Fig. 2). When chickadees had to compete with other (socially dominant to chickadees) species in the wintering avian community for feeder access, at sites 2 and 3 the lower feeder was significantly preferred and there was a suggested, if nonsignificant, difference between lower and upper feeder use at site 1 (Fig. 2). A similar pattern was observed during the 2006-07 winter (Fig. 3). In both winters at nearly all sites, intraspecific and interspecific competition for the restricted feeder port were usually intense, and birds rarely remained on feeder perches to husk sunflower seeds (this behavior was not systematically recorded). However, in the 2006-07 winter, chickadees often remained on feeder perches at site 2 to husk, making simple frequency of feeder visitation as a measure of height preference problematical for that site/year/species combination (Fig. 3).

Additional competition-based observations supporting a Black-capped Chickadee preference for the upper feeder included (data pooled over winters): (1) a chickadee displaced from an upper feeder perch or nearby branch by a non-chickadee social dominant moved immediately and directly down to the lower feeder $(n=33)$; (2) a chickadee arrived at a branch adjacent and near to the upper feeder, observed a non-chickadee social dominant at that feeder, and

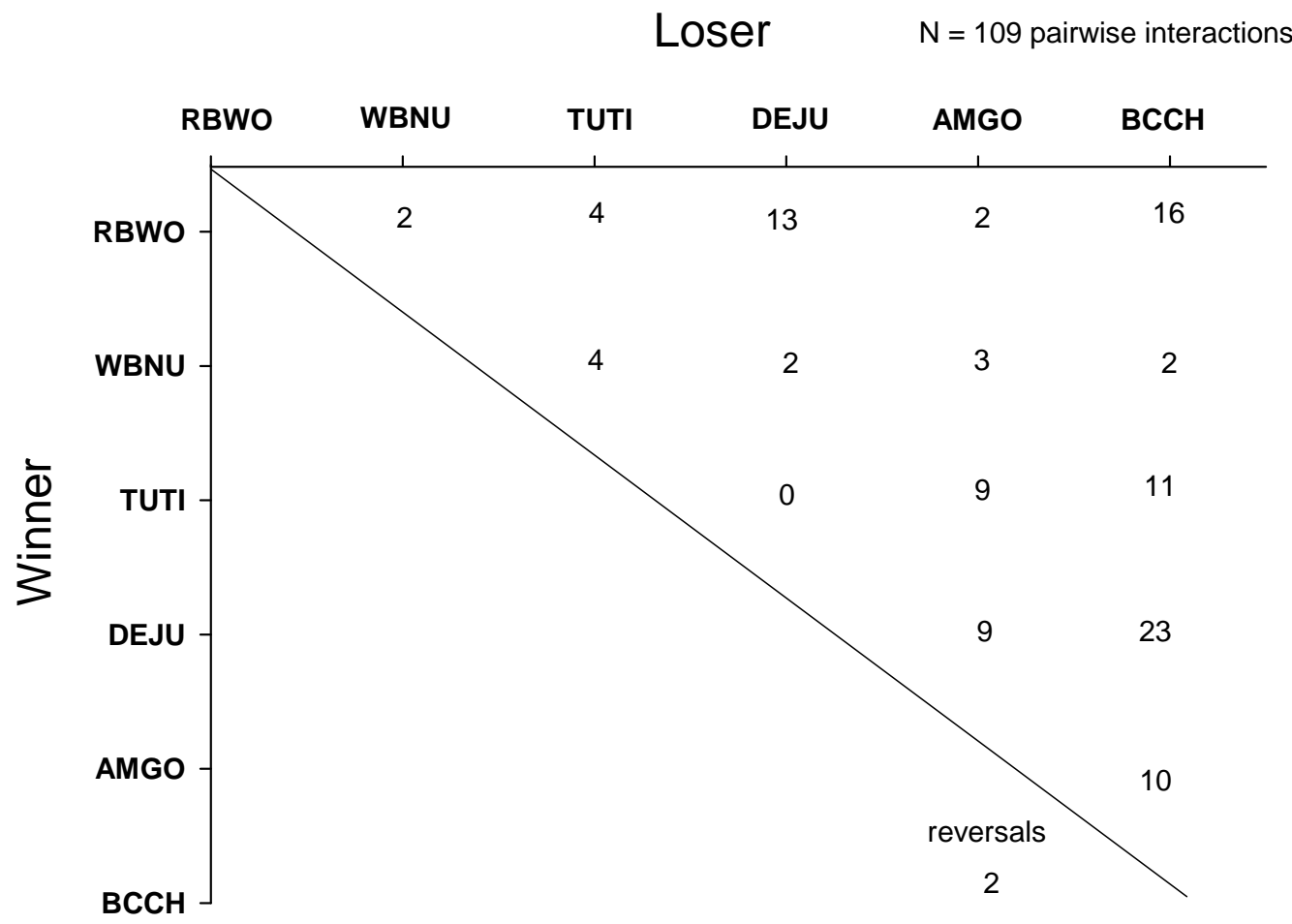

Fig. (1). Interspecific dominance hierarchy at winter feeding stations in south-central Kansas. RBWO -Red-bellied Woodpecker, WBNU White-breasted Nuthatch, TUTI - Tufted Titmouse, DEJU - Dark-eyed Junco, AMGO - American Goldfinch, BCCH - Black-capped Chickadee. Number of interactions within species pairs are indicated by winner and loser. Mean body mass \pm 1 SE, grams (afternoon-caught birds): RBWO - 82.4 $\pm 2.2, \mathrm{n}=8$; WBNU $-20.4 \pm 0.2, \mathrm{n}=11$; TUTI $-22.8 \pm 0.5, \mathrm{n}=15 ; \mathrm{DEJU}-19.6 \pm 0.2, \mathrm{n}=53$; AMGO $-14.6 \pm 0.4, \mathrm{n}=5$; $\mathrm{BCCH}-12.9 \pm 0.13, \mathrm{n}=58$. 


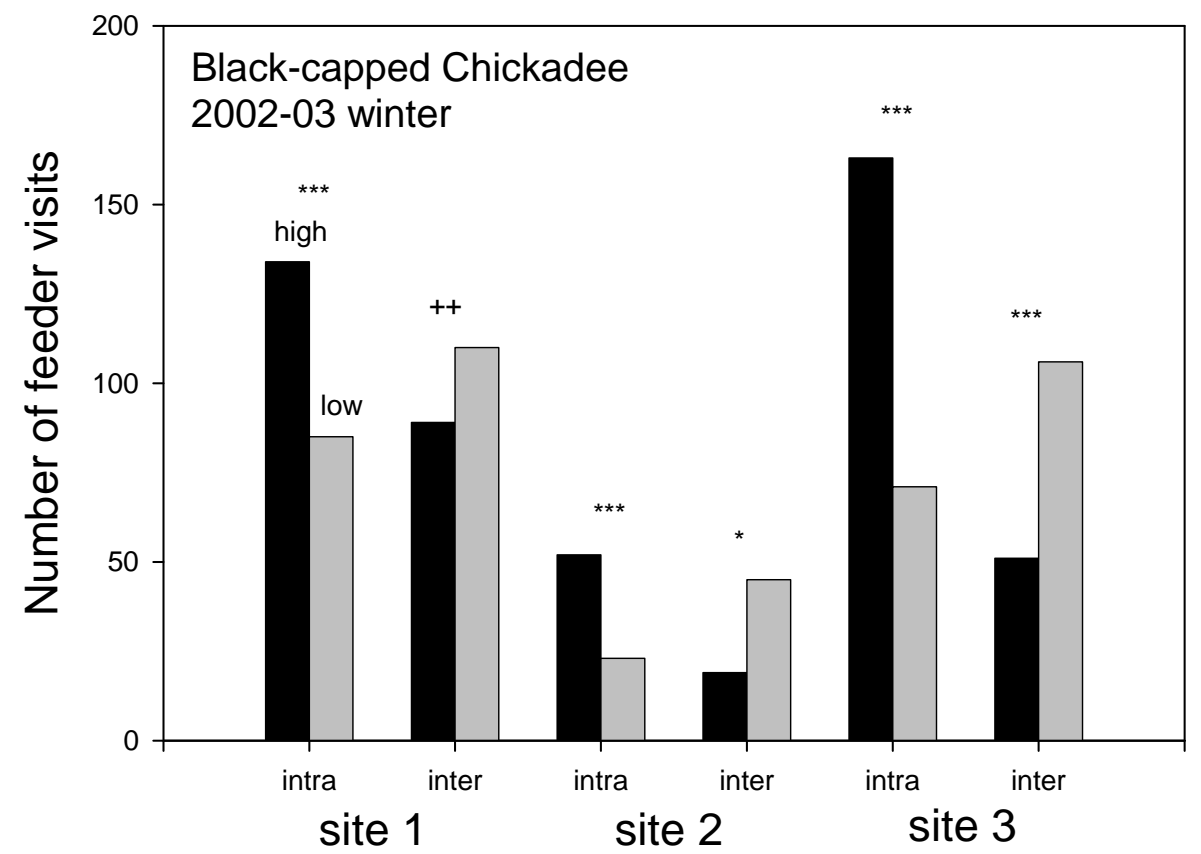

Fig. (2). Black-capped Chickadee feeder use, winter of 2002-03, sites 1-3. Intra - feeding (competing) only with conspecifics: inter - feeding (competing) with conspecifics and interspecific competition. Symbols: $* \mathrm{P}<.05$, *** $\mathrm{P}<.001,++\mathrm{P}<.15 . \chi^{2}$ values, left to right: 10.964 , $2.216,11.213,10.563,37.171,19.268$.

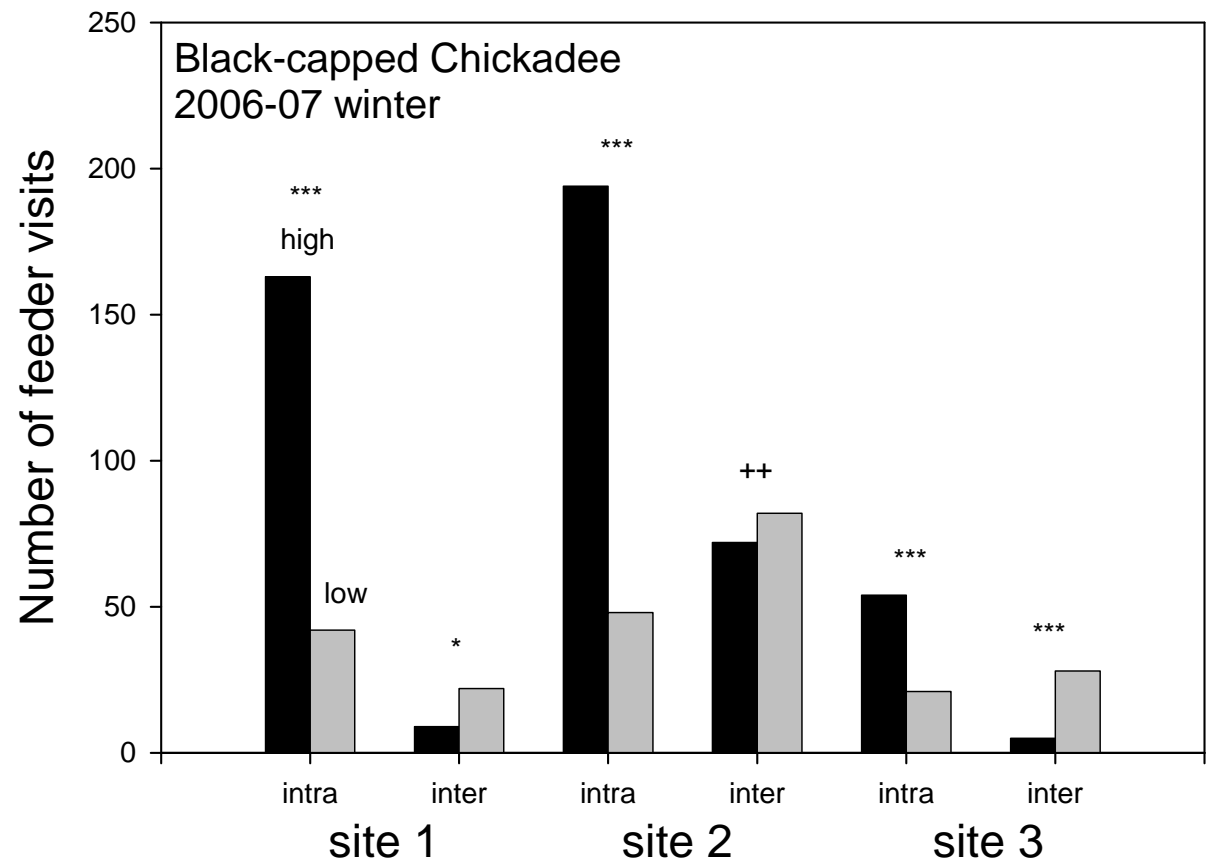

Fig. (3). Black-capped Chickadee feeder use, winter of 2006-07, sites 1-3. Details as in Fig. 1. $\chi^{2}$ values, left to right: 71.420, 5.542, 88.803, $0.649,14.520,16.030$.

moving directly down to the lower feeder $(n=8)$, (3) a chickadee feeding at the lower feeder while a non-chickadee social dominant fed at the upper feeder, then the chickadee immediately move to feed at the upper feeder $(n=1)$.

\section{Feeder Use by the Tufted Titmouse}

Among Tufted Titmice feeding only with conspecifics, three of four year-site combinations with $\mathrm{n}$ observations $\geq 10$ showed a statistically significant preference for the upper feeder, while the fourth year-site combination was margin- ally significant for upper feeder preference (Fig. 4). When feeding with other bird species socially dominant to titmice, two of three year-site combinations yielded a significant preference for the lower feeder, with a third combination nonsignificant at $\mathrm{P}<0.15$ (Fig. 4).

\section{Feeder Use by the White-Breasted Nuthatch}

Among White-breasted Nuthatches feeding alone or with conspecifics, both site-year combinations with $\mathrm{n} \geq 10$ 


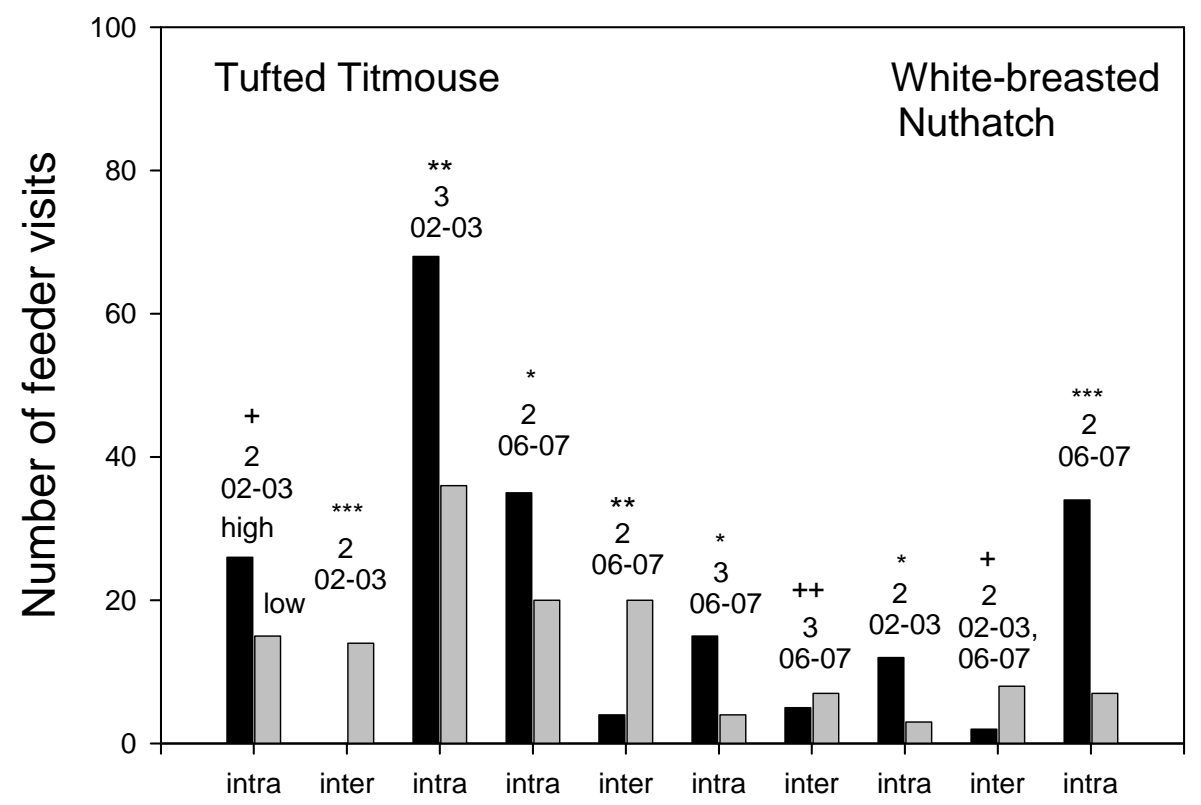

Fig. (4). Tufted Titmouse and White-breasted Nuthatch feeder use. Winter and site indicated. $\chi^{2}$ values, left to right: $2.951,14.000,9.846$, 4.091, 10.667, 6.638, 0.333, 5.400, 3.600, 17.781. Additional symbols: ** $\mathrm{P}<.01,+\mathrm{P}<.10$.

showed a statistically significant preference for the upper feeder; the sole combination with nuthatches feeding in the presence of a social dominant showed a marginally significant preference for the lower feeder (Fig. 4). Nuthatches rarely fed in the presence of other species.

\section{DISCUSSION AND CONCLUSION}

\section{Interspecific Dominance Hierarchy}

As expected, the interspecific dominance hierarchy was related to body size, with larger birds consistently dominating smaller birds. In the present study, samples sizes for a given species pair were occasionally small, but in such cases the larger bird always dominated the smaller, a pattern observed in other temperate-zone winter bird communities [2630], as well as in other ecological assemblages of birds [31, 32], birds and mammals [33], mammals [34], lizards [35] and fish [36].

\section{Feeder Height Preference}

A typical pattern observed in the present study in three common members of the tree-feeding guild in eastern North America is consistent preference for feeding at the upper feeder when a species faces only intraspecific competition for feeder use. A secondary pattern is switching to either preference for the lower feeder, or no feeder preference, with interspecific competition (vs. a social dominant) added. Feeder switching was on a minute-minute (or within-minute) basis, with foraging birds making short-term behavioral decisions about what feeder to select. Evidence for this includes birds often watching near an upper feeder with a social dominant present, and waiting to take a turn feeding there while the lower feeder was unattended by any species. Additionally, social dominants were regularly observed to displace members of subordinate species away from the upper feeder, whereupon subordinates chose the lower feeder. This general pattern was observed, especially in the chickadee, in a diversity of habitat conditions including forest edge and immature deciduous (leafless in winter) forest overlying a thick evergreen juniper shrub layer. It is possible that perceived predation risk is lower in the higher portions of this typical set of habitats, and birds prefer to feed there in winter as few other benefits of feeding at the slight height difference can be detected. At all three sites, especially site 1, cover was thicker lower to the ground than higher. Thus members of the tree-foraging guild at the study site appear to prefer to feed under relatively open conditions, perhaps to be better able to see predators $[37,38]$.

A high foraging height ostensibly preferred for purposes of minimizing predation risk has been show in previous studies [28, 39-41], including evidence of dominant species displacing subordinate species from higher (safer) foraging positions in trees [29, 42, 43]. All of these studies are of mixedspecies flocks studied in Europe. In an experiment similar to the one in the present study, members of the wintering mixed species flock in an Illinois woodland selected a high feeder most of the time over a similar lower feeder [44]. Thus on two continents in the north temperate zone, wintering bird species apparently perceive higher feeding sites to be safer than lower ones. In all studies, the typical predator was an Accipiter hawk species and/or the Pygmy Owl (G. passerinum). An interesting exception occurred in Alberta, where an opposite pattern was observed with a different predator, the Northern Shrike (L. excubitor). Within intact winter flocks of Black-capped Chickadees, socially dominant males foraged lower than subordinate females; this pattern was reversed when males were temporarily removed, and reestablished with male reintroduction [45]. Unlike Accipiter hawks (personal observation) and pygmy owls [46], shrikes attack in the upper canopy [45]. Thus there is a clear and dynamic relationship between foraging height preferred by wintering birds and hunting behavior of dominant predators. This conclusion is best considered a hypothesis, awaiting further confirmation, perhaps by direct manipulation of predator presence via model presentation. 


\section{Potential Sources of Error}

Site 3 is useful for considering possible effects of an observation blind and microenvironment on selected feeder use and winter foraging height. Here a blind was used, but it was placed in tall grass and forbs $100 \mathrm{~m}$ from the two feeders under observation. Feeders at site 3 were placed along a south-facing forest edge, hence they both experienced the same amount of direct sunlight. They did differ in wind exposure, with wind velocity generally being greater higher as is typical, due to friction with the ground. Wintering birds preferred the higher feeder, despite greater wind speed there. It thus appears that wintering birds are willing to forego some energy saving as would be afforded by lower feeder use (lower wind speed) in order to gain a better view of their surroundings, at least when using supplemental winter food sources.

The actual time individual birds spent at a feeder during a given feeder visit was not measured. Visiting birds nearly always took a seed and left to husk it in nearby cover. This was due to the nearly continuous presence of intraspecific and interspecific competition at the feeders. However, at site 2 in the 2006-07 winter, chickadees regularly remained on the feeder perch to husk single sunflower seeds.

Feeder sites 1-3 were all different habitat types, thus the possibility of habitat type differentially influencing feeder choice (upper or lower) can be considered. Each experimental feeding station was located in a habitat commonly occurring in the surrounding landscape, and all three were used regularly during foraging circuits of winter mixed-species flocks in late fall and early winter before experimental feeders were established, and in previous winters (Materials and Methodology). Indeed, habitat sites at which feeders were placed were carefully chosen to be representative of typical nonbreeding habitat. The most reliable conclusion is that wintering birds preferred the higher feeder across a variety of regularly used nonbreeding habitat types.

\section{Implications for Resource-Based Tests of Adaptive Body Mass Models}

Optimal body mass models of the avian nonbreeding period predict that size of the winter fat reserve of birds will increase with decreasing resource predictability [1-4]. Field tests of the models have relied on local variation in surrogate measures of resource predictability, including altitudinal [19, $20]$ and vertical gradients [21, 22]. In the latter case, when fat was greater in ground-foraging species than in treeforaging species, this difference was assumed to be due in some way (proximate and/or ultimate) to the vertical gradient of snowfall, with the ground-feeding but not the treefeeding guild experiencing unpredictable snowfall covering food resources. These comparisons have been instrumental in testing optimal body mass theory. An untested assumption of these general comparative tests is that the overall cost of fat storage does not vary with foraging guild. The main costs of fat storage are likely increasing exposure to predators and/or mass-dependent fattening. One possibility violating this assumption is the tree-foraging guild experiences greater predation risk (cost) than the ground-foraging guild, and that any intgerguild difference in fat level may reflect differential costs, minimizing if not eliminating any role for resource predictability, a chief underpinning of the models them- selves, and the resource-based behavioral perspective they have generated.

Is there a guild difference in fat cost that might serve as an alternative hypothesis? Consideration of this question is based on existing optimal body mass theory [1-4], which assumes that fat confers significant costs, which when high, restricts size of the fat reserve. The present study agrees with previous studies from two continents suggesting that in winter, tree-feeding bird species may in fact experience lower predation risk than ground-feeding species. This is an inference, as predation risk was not directly measured in both guilds, but it is consistent with other field studies of wintering birds [39]. Hence resource unpredictability may play a role in determining guild-specific avian fattening strategy. Tree-feeding species choose not to fatten extensively under predictable resources, even when costs of fat are relatively low. This underscores the lack of significant benefit to fattening (beyond meeting most nocturnal thermoregulation needs [21]) in this specialized foraging guild. Furthermore, members of the ground-foraging guild fatten significantly more than tree-feeders in winter [21, 22], even under relatively high cost of fat storage. In this guild, fat apparently confers a significant benefit. On the basis of the present experimental evidence from wintering tree-feeding species, high predation risk is assumed for the ground-foraging guild at the study sites; it seems unlikely that predation risk would be low high in the winter canopy (upper feeders), decrease toward the ground (lower feeders), and suddenly increase for species that spend much time feeding directly on groundborne food.

Finally, recent laboratory experiments on wintering birds [47, 48] and one field study [49] have suggested that increased predation risk can actually increase fat level, due to an interruption in foraging, although this effect is not universal [50]. These are artificial limited environments or unusual two-predator systems, with atypically high potential predation risk. Future resource-based tests of optimal body mass models should attempt to measure (1) both costs and benefits of fattening in different foraging guilds occupying different resource environments, and (2) what effect (increase or decrease) increased predation risk has on avian winter fat levels in natural environments.

\section{ACKNOWLEDGEMENTS}

Thomas Shelite and Rejeana Heath-Coss are thanked for field assistance. This is contribution Number 6 from the Ninnescah Field Station.

\section{REFERENCES}

[1] Lima SL. Predation risk and unpredictable feeding conditions: Determinants of body mass in birds. Ecology 1986; 67: 366-76.

[2] Houston AI, McNamara JM. A theoretical investigation of the fat reserves and mortality levels of small birds in winter. Ornis Scand 1993; 24: 205-19.

[3] Bednekoff PA, Houston AI. Optimising fat reserves over the entire winter: a dynamic model. Oikos 1994; 71: 408-15.

[4] Houston AI, McNamara JM. Models of adaptive behaviour. 1999. Cambridge, United Kingdom.

[5] Witter MS, Cuthill IC. The ecological costs of avian fat storage. Phil Trans Royal Soc Lond 1993; 340: 73-92.

[6] Witter MS, Cuthill IC, Bonse RHC. Experimental investigations of mass-dependent predation risk in the European Starling, Sturnus vulgaris. Anim Behav 1994; 48; 201-22. 
[7] Gosler AG, Greenwood JJD, Perrins CM. Predation risk and the cost of being fat. Nature 1995; 377: 621-3.

[8] Kullberg CS, Fransson T, Jacobsen S. Impaired predator evasion in fat blackcaps (Sylvia atricapilla). Proc Royal Soc London B 1996; 263: 1671-75.

[9] Lind J. Escape flight in moulting tree sparrows (Passer montanus). Funct Ecol 2001; 15: 29-35.

[10] Macleod R. Why does diurnal body mass change not appear to affect the flight performance of alarmed birds? Anim Behav 2006; 71: 523-30.

[11] Ekman J, Hake A. Monitoring starvation risk: adjustments of body reserves in greenfinches (Carduelis chloris L.) during periods of unpredictable foraging success. Behav Ecol 1990; 11: 62-7.

[12] Bednekoff PA, Biebach H, Krebs JR. Great tit fat reserves under unpredictable temperatures. J Avian Biol 1994; 25: 156-60.

[13] Bednekoff PA, Krebs JR. Great Tit fat reserves: effects of changing and unpredictable feeding day length. Funct Ecol 1995; 9: 457-62.

[14] Witter MS, Swaddle, JP, Cuthill IC. Periodic food availability and strategic regulation of body mass in the European starling, Sturnus vulgaris. Funct Ecol 1995; 9: 568-74.

[15] Gosler AG. Environmental and social determinants of winter fat storage in the great tit Parus major. J Anim Ecol 1996; 65: 1-17.

[16] Cuthill IC, Houston AI. In: Krebs JR, Davies NB, Ed. Behavioural ecology, 4th ed. Oxford, Oxford University Press 1997; 97-120.

[17] Cuthill IC, Maddocks SA, Weall CV, Jones EKM. Body mass regulation in response to changes in feeding predictability and overnight energy expenditure. Behav Ecol 2000; 11: 189-95.

[18] Rogers CM, Reed AK. Does avian winter fat storage integrate temperature and resource conditions? A long-term study. J Avian Biol 2003; 34: 112-18.

[19] Rogers CM. Experimental evidence for temperature-dependent winter lipid storage in the Dark-eyed Junco (Junco hyemalis oreganus) and the Song Sparrow (Melospiza melodia morphna). Physiol Zool 1995; 68: 277-89.

[20] Smith RD, Metcalfe NB. Diurnal, seasonal and altitudinal variation in energy reserves of wintering Snow Buntings. J Avian Biol 1997; 28: 216-22.

[21] Rogers CM. Predation risk and fasting capacity: Do wintering birds maintain optimal body mass? Ecology 1987; 68: 1051-61.

[22] Rogers CM, Smith JNM. Predation risk and fasting capacity: Local trade-offs in body mass of wintering birds? Ecology 1993; 74: 41926.

[23] Rogers CM, Heath-Coss RM. Effect of experimentally altered food abundance on fat reserves of wintering birds. J Anim Ecol 2003; 72: 822-30.

[24] Field guide to the birds of North America. $4^{\text {th }}$ ed. National Geographic Society; 2002

[25] Thompson MC, Ely C. Birds in Kansas. vol 1. Museum of Natural History, University of Kansas; 1989.

[26] Morse DH. Ecological aspects of some mixed-species foraging flocks of birds. Ecol Monogr 1970; 40: 119-68.

[27] Hogstad O. Differentiation of foraging niche among tits, Parus sp., in Norway in winter. Ibis 1978; 139-46.

[28] Suhonen J. Risk of predation and foraging sites of individuals in mixed-species tit flocks. Anim Behav 1993; 45: 1193-8.
[29] Carrascal LM, Alonso CL. Habitat use under latent predation risk. A case study with wintering forest birds. Oikos 2006; 112: 51-62.

[30] Ohsako Y. Spacing patterns and winter dominance relationships among three species of wagtails. Jpn J Ornithol 2001; 50: 1-15.

[31] Stiles FG, Wolf LL. Hummingbird territoriality at a tropical flowering tree. Auk 1970; 87: 467-91.

[32] McNally R, Timewell CAR. Resource availability controls birdassemblage composition through interspecific aggression. Auk 2005; 122: 1097-111.

[33] French AR, Smith TB. Importance of body size in determining dominance hierarchies among diverse tropical frugivores. Biotropica 2005; 96: 96-101.

[34] Rychilik L, Zwolak R. Interspecific aggression and behavioral dominance among four sympatric species of shrews. Can J Zool 2006; 684: 434-48.

[35] Langkilde T. Competing for crevices: interspecific conflict influences retreat-site selection on montane lizards. Oecologia 2004; 140: 684-91.

[36] Nakano S, Furukawa-Tanaka T. Intra- and interspecific dominance hierarchies and variation in foraging tactics of two species of stream-dwelling chars. Ecol Res 1994; 9: 9-20.

[37] Lima SL, Wiebe KL, Dill LM. Protective cover and the use of space by finches: is closer better? Oikos 1987; 50: 225-30.

[38] Lima SL. Protective cover and the use of space: different strategies. Oikos 1990; 589: 151-8.

[39] Ekman J. Tree use and predator vulnerability of wintering passerines. Ornis Scand 1986; 17: 261-7.

[40] Kullberg C. Spatial niche dynamics under predation risk in the Willow Tit Parus montanus. J Avian Biol 1998; 29: 235-40.

[41] Suhonen J. Predation risk influences the use of foraging sites by tits. Ecology 1993; 74: 1197-203.

[42] Ekman JB, Askenmo CEH. Social rank and habitat use in willow tit groups. Anim Behav 1984; 32: 508-14.

[43] Ekman J. Exposure and time use in willow tit flocks: the cost of subordination. Anim Behav 1987; 35: 445-52.

[44] Lee Y, Kuo Y, Bollinger EK. Effects of feeding height and distance from protective cover on the foraging behavior of wintering birds. Can J Zool 2005; 83: 880-90.

[45] Desrochers A. Sex, dominance, and microhabitat use in wintering black-capped chickadees: A field experiment. Ecology 1989; 70: 636-45.

[46] Kullberg C. Strategy of the pygmy owl while hunting avian and mammalian prey. Ornis Fenn 1995; 7: 72-8

[47] Lilliendahl K. Yellowhammers get fatter in the presence of a predator. Anim Behav 1998; 1335-40.

[48] Pravosudov V, Grubb TC Jr. Management of fat reserves in tufted titmice Baelophus bicolor in relation to the risk of predation. Anim Behav 1998; 56: 49-54.

[49] Krams I. Length of feeding day and body weight of great tits in a single- and a two-predator environment. Behav Ecol Sociobiol 2000; 48: 147-53.

[50] Carrascal LM, Polo V. Coal tits, Parus ater, lose weight in response to chases by predators. Anim Behav 1999; 58: 281-5. 